\title{
Constraints-led Approach and Emergent Learning: Using Complexity Thinking to Frame Collectives in Creative Dance and Inventing Games as Learning Systems
}

\author{
Timothy Hopper*
}

Faculty of Education, University of Victoria, School of Exercise Science, Physical and Health Education, University of Victoria, PO Box 3015 STN CSC, VICTORIA. BC. V8W 3P1, Canada

\begin{abstract}
This paper will describe complexity theory as framing an emergent learning process. This process will be connected to a constraint-led approach to skill learning and a non-linear pedagogy perspective in physical education[1]. Often traditional and common sense notions of learning are framed as a correspondence process focused on acquiring or accumulating information such as repetition of technical cues in PE to do a skill in an activity. In this paper I will elaborate on a broader conception of learning systems, shifting concepts of learning from correspondence to coherence theories of knowing, where learning is described as an emergent process. By way of examples, this paper will discuss how pedagogical approaches associated with creative dance [2] and inventing games [3]can form complex learning systems that can be understood using complexity thinking.
\end{abstract}

Keywords: Complexity thinking, Learning system, Emergence, Physical Education, Dance, Games, Constraints-led approach, Non-linear pedagogy.

\section{INTRODUCTION}

The purpose of this paper is to develop an expanding understanding of the learning in PE as more situated, social, complex and framed by spaces that enabling learners to succeed. In this paper I examine how complexity thinking allows us to create a broader and more contextually responsive notion of learning. This paper draws on my previous work with colleagues applying complexity thinking to learning in videogames and teaching games for understanding (TGfU) lessons [4, 5], in creative dance [6] and recent work exploring inventing games (IG) in PE [3].

Drawing on Mennin [7] the terms "agent" and "attractor" will be used to explain complex systems.Agents in a complex system are seen as something that takes part in an interaction of a system and is itself subsequently changed: a person, a team, a nerve cell, a student, a teacher, etc. Individual agents interact at the local level, they do not know the system as a whole nor does a central agent have responsibility for overall control of the system. Agents in a system come together based on an attractor, a common intent or purpose. The term "attractor" is used to describe the "pattern or activity in time in a region of space that 'appears' to draw the energy of a system to it” (p. 838). An attractor is the common factor that draws and energizes agents to act together forming a complex system.

*Address correspondence to this author at the Faculty of Education, University of Victoria, School of Exercise Science, Physical and Health Education, University of Victoria, PO Box 3015 STN CSC, VICTORIA. BC. V8W 3P1, Canada; Tel: 1250721 8385; Fax: 1250721 6601;

E-mail: thopper@uvic.ca
By way of offering pedagogical examples of applying complexity thinking to physical education I will draw on dance and inventing games (IG). Creative dance was developed from the "dance for all" ideas advocated by Rudolf Laban [2]. It focuses students on generating expressive movement solutions to problem-based stimuli structured by the teacher. Inventing games, as part of TGfU approach, represents a shift from the development of techniques with highly structured lessons to a game centered approach where learners are introduced to designing their own games to initiate tactical and skill learning from engaged game playing [8, 9].

\section{FRAMING DIFFERENT LEARNING POSITIONS}

As noted by Light [10] learning is more than information processing; rather it is an embodied adaptation of the learner where cognition extends beyond the mind as a separate entity to include the body and all its senses. Traditionally, and often common sense notions of learning separate the mind from the body, offering a simplistic notion of correspondence between internal knowing to external reality [10]. Correspondence theories or entity-based theories of learning "placed knowledge in the head of the learner, which led to the creation of educational systems that focused on transmitting content into individual minds" [11]. Instead, coherence theories of learning frame learning as an emergent perspective that results from the active relationship of individuals and the environment a "dynamic transaction among the individual, the physical environment, and the socio-cultural context” (p. 174). 
As outlined by Davis, Sumara and Luce-Kapler [12] learning positions can be divided into two broad camps. Correspondence theories are associated with behaviorism and mentalism. These theories focus on mechanical, cause-effect dynamics with learning understood as predictable, as possible to manipulated and where it is taken for granted that all learning happens in the heads of individuals. A key idea is the closeness of match between subjective (internal) models and objective (external) reality.In contrast, coherence theories like constructivism, social constructivism (also social constructionism), cultural critical discourse and ecological theories all focus on fit of personal construal (reading) with a changing context and other individuals' ideas. A key idea in these theories is that through experiences, artifacts, or interpretive possibilities, individuals tend to construe some manner of adequate connection with what they know to what they are engaging with in a continuous process of adapting.

\section{Correspondence Theories of Learning}

Behaviorism is focused on what is observable and measurable. Learning is framed in terms of what someone is doing, not what they are thinking. In this position the focus is on training agents to make certain desired associations through the careful administration of rewards, promises of gain, punishments, and threats of punishment. Behaviorists soundly demonstrated some important and enduring principles of learning, including that context is always critical and that conscious awareness is not always necessary for learning to happen. However, as noted by Davis et al. (2008) this approach ignore that (1) the diversity of contemporary schools makes determining learning very complex, (2) individual human learning cannot be predetermined, (3) learning is not linear, and (4) humans learn from personal interest not by being forced by an external influence.

Mentalism refers to a broad range of information processing theories (related to cognitive science) that rely on the premise that learning is a matter of building an internal model or representation of an external reality. The most common metaphor across mentalist theories is the computer with phrases like inputting information, storing and processing knowledge and outputting ideas. Davis et al. [12] 5 comments that a common critique of mentalist theories is core notion of internal representations, if you look inside someone's head you do not find a representation of the world. Learning is not about taking things in or assembling a model of the external world in your head, it is way more complex.

Though both of these positions seem opposite they are based on a correspondence assumption about learning focused on internal/external dichotomies and learning as linear and pre-determined; seeking to control inner representations by minimizing ambiguity. Good teaching thus tends to be perceived in terms of highly structured curriculum sequences and instructional procedures with teaching focused on order, planning, prediction, management and evaluation. At face value this sounds reasonable and often external bodies to schools impose this type of curriculum ignoring the com- plexities of human cognition and, in the process, oversimplify the complexities of teaching and learning.

\section{Coherence Theories of Learning}

Coherence theories reject the separation between mind/body, internal/external or human/nonhuman. Instead coherence theories focus on how the context affords the ability for a person to find coherence in their actions and meaning making. The difference in these coherence theories from earlier correspondence theories of learning is that they are organized around the assumption that what really matters is internal coherence, what makes sense to the individual. As Davis et al., [12] explains, "For a system to be viable, its parts must be compatible with one another-and it really doesn'tmatter if they match, reflect, represent, model, orotherwise correspond to a realm beyond the system.” These theories are therefore focused on adaptation, evolution and best fit of the learning system to the realm beyond the system.

Constructivism theory, attributed to Jean Piaget, focuses on the personal sense individuals make of the world [13]. Metaphorically it has been seen as a process of constructing an adequate fit, however, this metaphor may be limited and a better idea is a continuous construing - adjusting and adding on [14]. Piaget argued that learning is a continuous process of updating one's sense of the world as prompted by new experiences.

Social constructivism (or constructionism) theories are concerned more with interpersonal dynamics and collective activity than with the focus on personal construal associated with constructivism. Social constructivism theories focus on the individual adapting in a social system. An individual learns through joint participation in creating a community and society. Informed mainly by the work of Russian socio psychologist Lev Vygotsky [15, 16], this theory focuses on the processes by which individuals become a participant in a certain community of practice. The focus in these theories is often on situated learning through co-participation in communities of practice [17]. Social constructivism focuses on individuals as a learning system within a grander learning system whose learning is mediated by symbol systems such as language and social conventions of meaning making that enable and constrain cognition.

Cultural and Critical discourse theories focus on how the cultural process shapes and constrains learning, in other words, how we act and speak frames learning. These theories are interested in deeply entrenched habits of interpretation and implicit associations that support social constructions of constructs such as gender, race, class, sexuality, and ability. Issues of morality, social justice and ethical actions are raised in this learning position and can be associated to the work of Paulo Freire [18]; in particular his idea of “ 1987); in particular the effort to render explicit the cultural conditions that delimit possible worlds and acceptable identities"[12]. In this learning position it is not enough to critique problematic social phenomena, one must work with individuals and social collectives to consider and embody 
alternatives that allow a different construction of the world and different ways to engage.

Ecological theories have influenced a collection of learning theories (i.e., dynamic systems theory, situated cognition, ecological psychology) focused on the study of relationships, what Barab [19] refers to as a relational ontology considering "self-organizing or spontaneous ordering systems [where]... learner/participant interacts with the real world to address real dilemmas" (p. 353). Cognition is considered a biological event where the human species is a subsystem that learns as part of a larger more complex web of relations. In ecological learning theories an agent's knowing are those patterns that afford it coherence. As Davis et al. [12] notes "In particular, over the past 50 years, ecological studies have helped to highlight that many-and perhaps most—of the problems and crises that humans now face are rooted in untenable conceptions of the relationship of humans to the more-than-human world” (p. 106). Ecological learning theories consider organized systems such as bacterium and rainforests as learning systems, each influencing the other. The human learning system's thought/action are entwined with and implicated in the evolving structures of many other systems. This is why as Davis et al. notes "ecological theories help to explain why it seems like our knowledge corresponds to an external reality. Our knowledge fits with the world for the same reason that our lungs match the earth's atmosphere: They evolved and are evolving together” (p. 108).

Across all the coherence theories, a key assumption is that a phenomenon/state will persist until the effort required for the agent to maintain it exceeds the effort required to revise it. Teaching is then about creating the conditions for learning from experience, not filling up with information that might be useful. Learning becomes a reworking of an extensive web of relations that requires considerable effort. Such transformation can only be elicited after prompts for learning have reached "a certain 'critical mass' in order, first, to interrupt entrenched patterns and, second, to present viable alternatives to existing habits"[12]. We have noted that video games create the conditions for such prompts to learning offering risk free, trial/adaptation and continuous feedback loops on player engagements in the game [4, 20].

Complexity thinking operates as an umbrella across all these coherence theories. Each of coherence theories represents a instance of complexity thinking as we shift from construing individual (constructivism), community of construing individuals (social constructivism), culturally framed construing (cultural and critical discourse) and co-evolving human learning system with other learning systems (ecological perspectives). Considering the class collective as a learning system creates a co-evolving process between agents of the collective and between the collective and the context that affords it coherence. Complexity thinking then allows us to consider that learning is relative to how a system of agents, drawn together by an attractor, adapts to the environment that enables its system's continued existence. Good teaching then becomes about creating the conditions for learning, attracting agents together then encouraging collective explora- tion, discovery and awareness by "structuring experiences that engage, stimulate, and challenge - in brief, that promote individual and group self-regulation"[12]. The next section will explore how such a collection can become a learning system.

\section{Complexity Theory as the Study of Learning Systems}

As noted by Mason [21] complexity theory has developed principally in the fields of physics, biology, chemistry, and economics... [it] arises out of chaos theory in that it shares chaos theory's focus on the sensitivity of phenomena to initial conditions that may result in unexpected and apparently random subsequent properties and behavoir...[and] share concerns with wholes, with larger systems or environments and the relationships among their constituent elements or agents, as opposed to the often reductionist concerns of mainstream science."

Traditionally science has focused on reducing systems into parts assuming that the parts create the whole. In essence as Davis and Sumara [22] have commented, "complexity science is the study of learning systems" (p. 454) it offers a way of understanding human learning as more than discrete actions separate from context, but rather learning that emerges due to the way parts interact within human systems (self-organize), adapting and re-forming to meet the demands of a dynamic environment.

One of the most important insights of complexity theory is the notion of emergence. This is where given a sufficient degree of complexity, and in a particular environment new (often unexpected) properties and behavoir emerge. As Mason [21] notes, "The whole becomes...more than the sum of its parts in that the emergent properties and behavoir are not contained in or able to be predicted from the essence of the constituent elements or agents” (p. 33). Complexity science notes that once a complex system, interacting with the environment that affords it coherence, reaches a certain critical level of diversity a phase transition takes place, what Barab [19] calls an autocatalytic state. This state means that the system self-organizes in a continuous activity drawing on available resources as its constituent elements act together and in turn interconnect with the environment.

From this frame of reference learning will be understood from a relational ontology and referenced as expanding concepts that have evolved from correspondence frameworks such as behaviorism and cognitive mentalism to coherence frameworks associated with constructivism, social constructivism, cultural/critical discourses and ecological perspectives [12]. From coherence perspective, human cognition comes from joint participation in a complex web of relations, where order emerges from seemingly random elements (agents) that come together around a common purpose (attractor). In complexity theory learners form systems that are nested, inter-connected, diverse, afforded patterns of acting within constraints, subject to bottom-up organization from decentralized control, and develop skills from their comingle roles in the pursuit of a common goal [14]. 


\section{Features of Complex Learning Systems}

Complexity thinking suggests certain features needed to be present to allow a complex learning system to form. Fig. (1) summarizes these features with a brief explanation of each feature. A complex learning system forms in a nonlinear process and is based on the dynamic interactions between multiple variables, within indeterminate and transient systems, through a process of adaptation, self-organization and emergence in order to thrive in a changing environment [21]. Critically the system must contain enough diversity in its make-up to allow it the ability to adapt to demands of the environment, but there must also be enough redundancy (elements in common) between agents of the system so that if any part of the system fails the other agents can compensate. In addition, the system needs redundancy to facilitate neighborly interactions as the agents form a system, and through participation in the environment, develop skills in comingling roles associated with the intents of the system. As the complex system inter-acts it forms a relationship with the environment so when the conditions are just right an autocatakinetic process starts where the system draws on available resources in a self-sustaining exchange. The conditions in the environment need to offer enabling constraints that limit what the system can do to prevent it being overwhelmed, but at the same time offer an openness to possibilities that the complex system can take advantage of. The system must have the capacity to retain the products of previous exchanges, but also the ability to discard elements that are no longer useful. The system needs to form nested selfsimilar structures that emerge from inter-actions around simple rules that initiated the system's ability to dynamically unfold [14, 21].

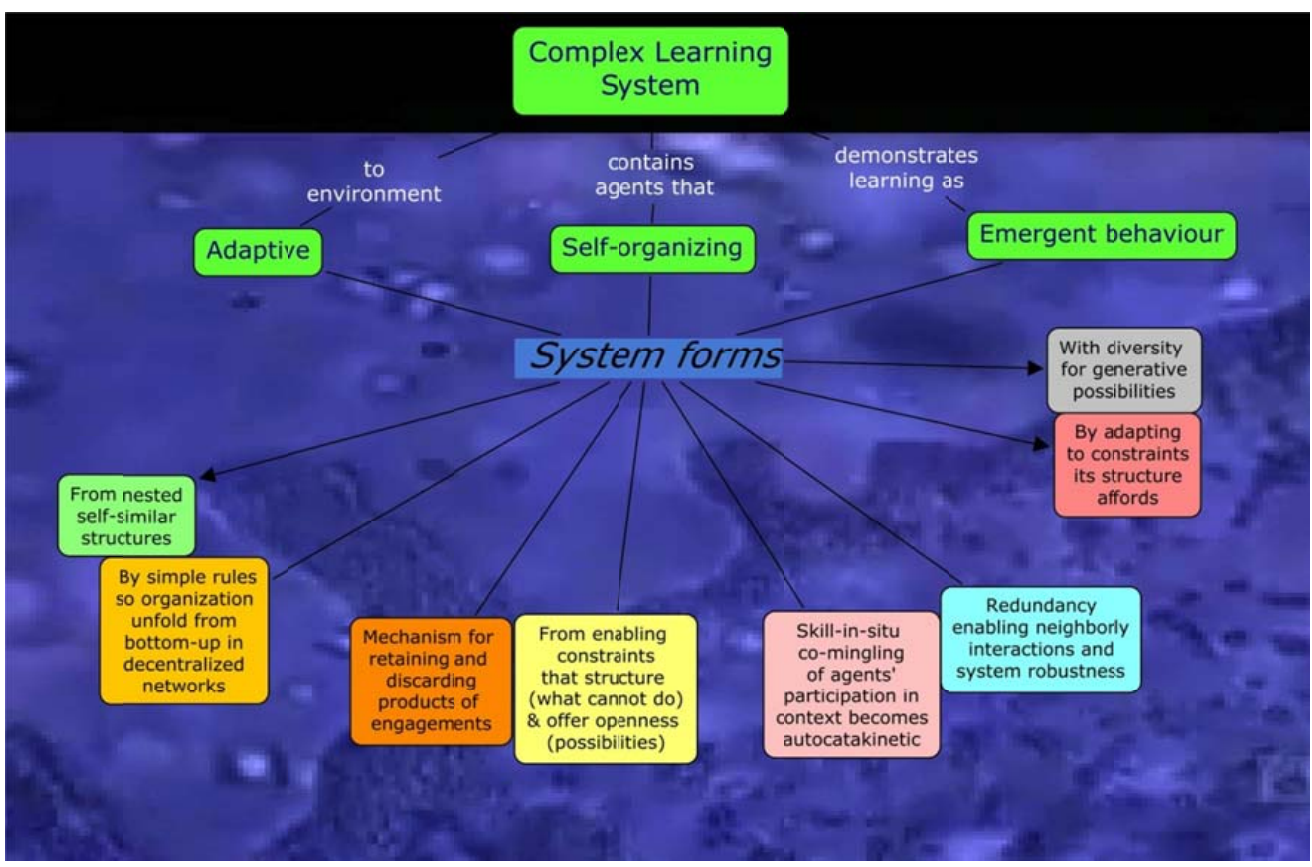

Fig. (1). Key features of complexity thinking.

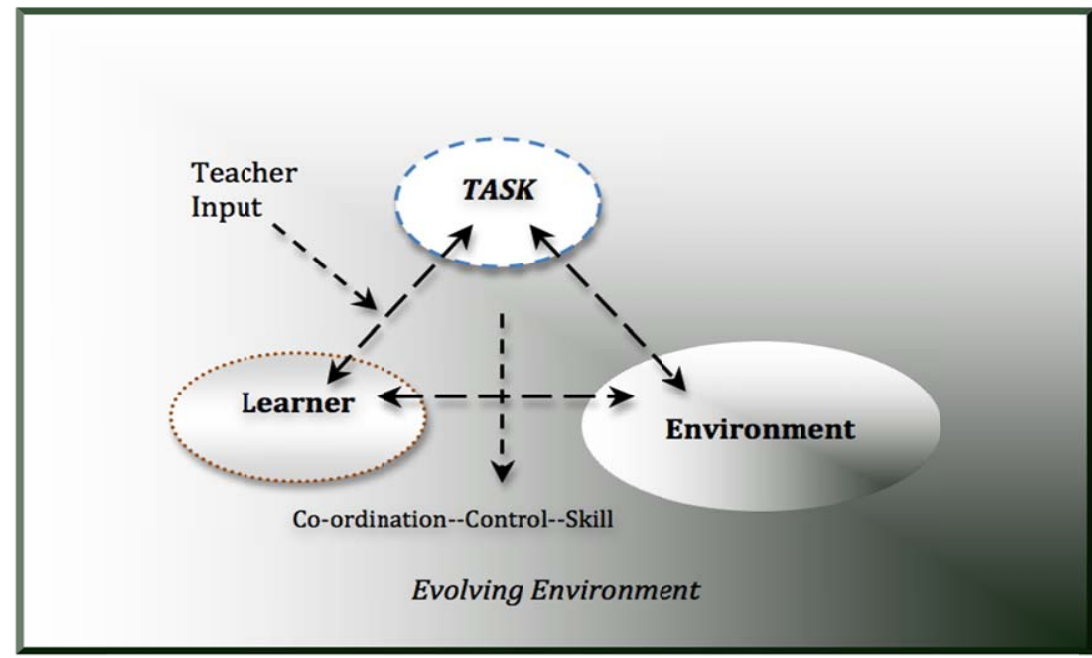

Fig. (2). Constraints model for complex skill learning using ecological task analysis. 
The features of a complex system can be seen in nature in the way birds form in flocks, ants create colonies, immune system deals with a virus and the way the chemicals react in certain conditions $[12,19,23]$. The last section of the paper will speculate on how these features can be applied to games and dance teaching and how complexity thinking connects to the constraint-led approach and non-linear pedagogy in teaching skills in PE [24].

\section{CONSTRAINTS-LED APPROACH FOR COMPLEX SKILL LEARNING}

Fig. (2) adapted from Newell's [25] ecological task analysis model offers a constraints-led approach to teaching motor skills in PE [1, 24, 26, 27]. Newell [25] classified constraints into three distinct categories performer (learner), environment and task. These constraints inter-act to shape degrees of freedom in learning within a non-linear process. This means that motor learning in particular is an ongoing dynamic process involving a "search for and stabilization of specific, functional movement patterns across the perceptualmotor landscape as each individual adapts to a variety of changing constraints"[24].

As noted by Davids et al. [24], Newell's model of motor learning implies three stages a learner goes through, adapting to environmental constraints in order to elicit a successful skill pattern; (1) co-ordination, (2) control, and (3) skill. As Renshaw et al. [27] explains, "constraints have been defined as boundaries which shape the emergence of behaviour from a movement system (e.g., learner) seeking a stable state of organization” (p. 4). The interaction of different constraints (action capabilities, task and environment) forces the learner to seek stable and effective movement patterns during goaldirected activity such as rallying a ball in a tennis-like game. Renshaw et al. continues, "through self-organization processes, inherent to many different biological systems including human movement systems, constraints can shape the emergence of movement patterns, cognitions and decision making processes in learners" (p. 4). Therefore, and due to the inter-connected nature of this learning process, small changes in one part of the system can lead to major changes emerging in the rest of the system. For example, if a dense high bouncing sponge ball is used rather than a tennis ball in a tennis-like activity then a previously over-whelmed learner may now have the time to adapt their movement patterns to the speed of the ball, becoming more successful, hence enhancing intrinsic motivation and encouraging them to engage more in the task.

Environmental constraints refer to physical factors surrounding the learners including gravity, altitude, light, music or noise as well as fixed structures such as floor space, court surface, net or lines on the area of play. A second important category of environmental constraints includes social factors like peer groups, social and cultural expectations. As noted by Renshaw et al. [27] "Such factors are of particular relevance for young learners, whereby motor learning is often strongly influenced by group expectations, trends and fashions, and the presence of critical group members such as the teacher or class-mates” (p. 6). As indicated by the shading in
Fig. (2), environmental constraints create background influences on the learner behavoir that interact with the task constraints to create challenges that become potential sites of learning. These challenges are continuously shifting based on the teacher inputs through tasks, verbal prompts (such as feedback and questions), manipulation of task constraints, adaptations made to a game structure and the actions of other learners in the environment.

The task constraints, mediated by the teacher, include the goal of the specific task, rules on actions or conditions on tasks, and the equipment used during the learning experience. Physical educators can manipulate task constraints like modifying equipment available to learners, or the size of playing areas, setting relevant task goals in games, beat/tempo in dance, imagery ideas or enforcing specific rules/conditions for performance. These mediating tasks can shape the emergence of learners' behavoir in physical education. For example, in the tennis-like activity where the learners are trying to rally a ball in a court, the sponge ball could be one task modification selected for the learner, the teacher may also add other constraints such as a higher net that causes the ball to be hit up and the ball to bounce higher giving the players more time to move and successfully return the ball into play. Other inputs on tasks from the teacher may be in the form of critical cues for a skill that build on stable movement patterns established by the learner such as cue of "focus on striking a falling ball in front of the body".

Referring to Fig. (2), and continuing with the tennis-like activity, the learner who is focused on keeping the ball in the court with one bounce would attempt to explore how to return a ball hit to them. This exploration would involve coordinating the relationships between key components of their dynamic movement pattern and the task/environmental constraints. Their body movement, arm/legs and trunk actions have to be co-coordinated with important perceptual-motor landscape cues. These cues include things such as ball speed, bounce, court surface, racquet swing and contact point, as well as direction and force to send the ball back into the court. Creating the appropriate time to process this information would rely on their positioning in relation to the court area where they expect the ball to be returned [28]. From exploration via multiple attempts for a beginner at a coordination level, a basic movement pattern emerges as the learner adapts previously used motor patterns to the task. Each leaner has unique performance characteristics that can be viewed as resources channeled by an individual to solve particular task problems or characteristics that can lead to individual-specific adaptations [24]. Critically here is the intrinsic motivation of the learner to do the task with the learner's prior history of doing similar type tasks operating as a rate limiter to their progress. The teacher has to mediate through prompts and further constraint modifications to facilitate the learner's ability to successful adapt. Eventually, within a group of learners, different movement solutions emerge as each individual adapts their unique actions to the constraints. These constraints afford them a certain degree of variability in their movement pattern to achieving the goal of the activity. 
This brief overview of the constraints-led approach articulates how an individual's learning is distributed across their actions and the constraints in the environment, and is therefore reflected in their ability to adapt their actions to the constraints [24]. Learning then emerges as a non-linear process where a "learner's co-ordination solutions are products of self-organization and that periods of movement variability should be valued as part of the learning process" (p. 98). Good teaching, like in complexity thinking, implies a nonlinear pedagogy that stresses the "importance of facilitating independent learning through search, discovery, and exploration of constraints” (p. 99). Skill learning is less about perfecting skill performance to an idealized motor pattern with feedback and carefully constrained practice environments, and more about creating enabling learning spaces. Such learning spaces would be mediated by the teacher but with more of a "hands off" approach, focused on connecting the learner to manipulation of their actions in relation to task/environment constraints.

Complexity thinking develops this idea further, offering a way of studying a collection of individuals learning from a contextual ontology. Learning in this instance is emergent in response to how learners, as part of a collective, adapt and self-organize in relation to the contextual constraints; a context their actions shape and reshape. In this way complexity thinking builds on the non-linear pedagogy ideas by focusing on the collective of individuals learning together in relation to a common attractor such as keeping the ball in the air after one bounce or expressing an imagery idea in a dance. This allows learning to be described in terms of living and social systems, creating a more dynamic interpretative process for understanding learning as emergent from experiences that transform learners as they collectively transform contexts of learning [29]. To conclude, complexity thinking, drawing on a non-linear pedagogy and a constraints-led approach, will be used to describe how a collection of individuals engage in complex, situated and social spaces that encourage their emergent learning in creative dance and inventing games.

To explain emergence I will highlight the key characteristics in complexity thinking that are present when learning to (1) teach a creative dance lesson, and (2) learn to play a game using an inventing games approach.

\section{CREATIVE DANCE AND COMPLEXITY THINKING: TEACHING PROCESS ENABLING COMPLEXITY THINKING PRINCIPLES}

Creative dance refers to teaching physical education by focusing students on exploring movement solutions to tasks based on a stimulus structured by the teacher [30, 31]. Rudolf Laban popularized creative dance in the 1960's and 1970's in the United Kingdom in an approach called "dance for all” [2]. He advocated "four principles-body concepts,

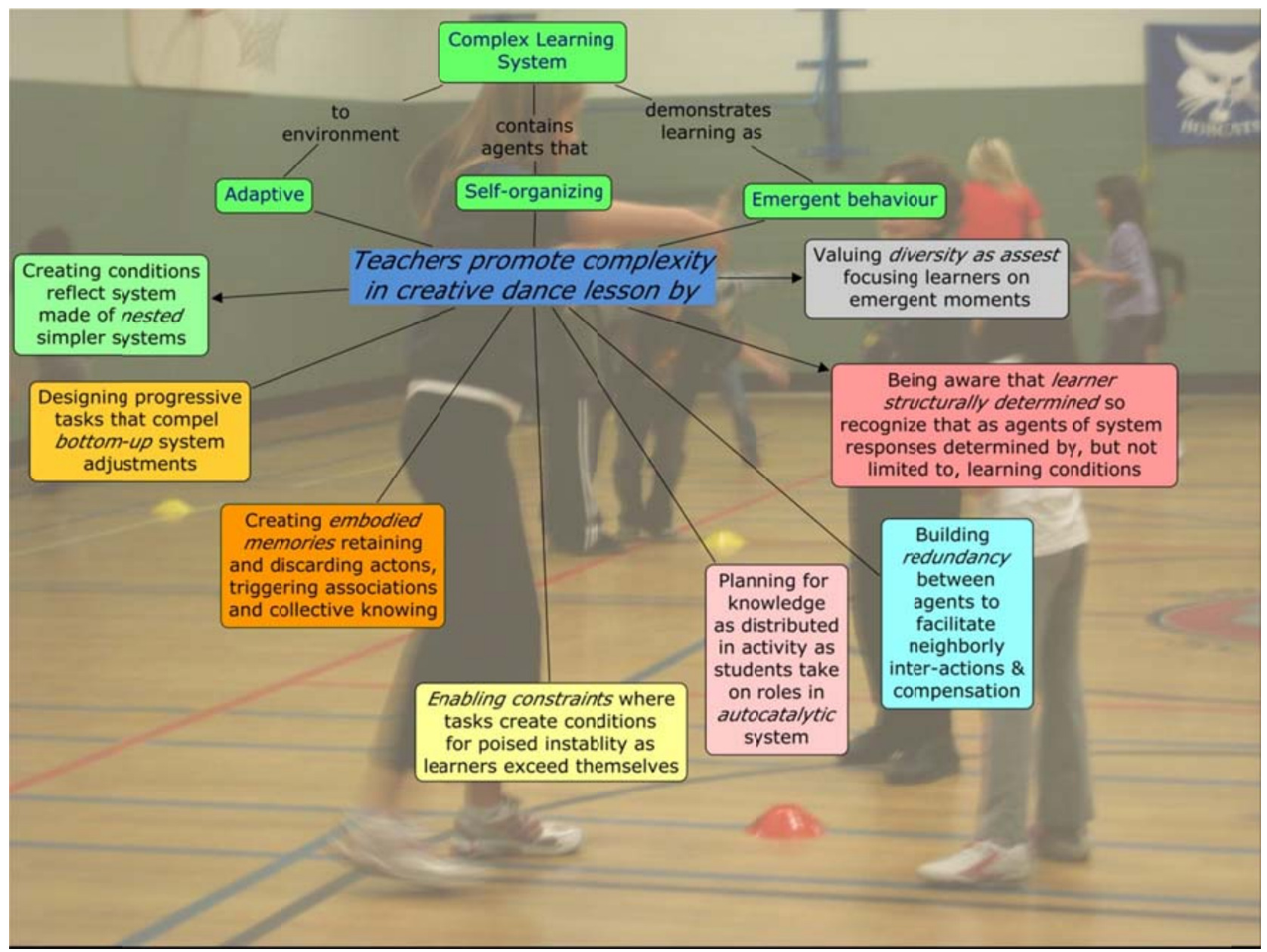

Fig. (3). Features of complexity thinking when teaching a creative dance lesson. 
effort concepts, spatial concepts, and relationship concepts[which] deal with what the body does, where it moves, how it moves, and with whom or what it moves" [emphasis added] (p. 7).

To help navigate the complexity thinking features that can be realized in teaching creative dance, Fig. (3) below builds on Fig. (2) showing how a teacher can promote features of a complex learning system. The core themes of adaptation to environmental/task constraints, self-organization of the collective of learners and emergent behaviour are noted as principles for the teacher to promote complexity in teaching creative dance.

Drawing in the ethnographic fiction first published in Hopper [6] I will link complexity thinking and non-linear pedagogy to the teaching of creative dance referring back to Fig. (3). The creative ethnographic non-fiction representation [32-34] is based on an interview with a pre-service teacher I had taught after her successful elementary school practicum experience where she was commended for a her teaching abilities in PE. This genre is used to represent an actual event that happened for the pre-service teacher, but names and contextual information have been changed and certain details highlighted such as situation, persona, character and scene to give the reader a virtual experience of the lesson [35]. The story captures how creative dance models a constraint-led, collective and emergent process of learning. The following is based on extracts taken from Hopper [6].

\section{Grade 6 Creative Dance Class - "The Class from Hell”}

Mindy smiled as the grade six class stormed into the gym. The principal who was also Mindy's supervisor for the practicum, had described them as the 'class from hell'. The girls in the class were reasonably well behaved but the boys, well they were an unruly bunch, many were big for their age, some were even bigger than Mindy; many of them were typical 'jock' boys.

Mindy wondered if the children had remembered that they were going to do creative dance. When she had explained the idea in the previous lesson, Jason, the leader of the unruly bunch, had said with a resistant stare; "Oh yeah, going to get us to be clouds are you?" What was going to happen? The principal must have wondered as well because she had come to watch.

Initially the conditions for learning seem threatening, as a teacher your instincts from traditional learning point of view would be to control, manage and centralize the learning process. However, Mindy had a good relationship with students formed in previous lessons. She had expected resistance but she knew that she could draw on group diversity as an asset, by guiding the students' responses by feeding back appropriate responses showing demonstrations and highlighting creative responses.

"We are going to do creative dance," Mindy started, "all I ask is that you give it a try. You might like it." As she spoke she caught every child's eyes, their faces stared back blankly. Exuding enthusiasm Mindy, with the music ready, launched into the lesson.

Initially, the children treated the whole episode as a lark, Jason's expression was 'forget it lady'. Gradually and coaxingly Mindy introduced the movement ideas to the children. First a fast walk, then a pivot, and then sleeping positions.

Mindy had previously done lessons in modified volleyball where the students had learned to appreciate each other's actions and have their efforts acknowledged. She had got the students playing together, focusing their attention one when members of their group had been successful and helped them learn from progressively developed tasks - she had created neighborly interactions between the students. These experiences had created a redundancy between the students, a common understanding that helped to create the system that was Mindy's PE lessons, but this was the first time the students had done dance. The action words "fast walk" and "pivot" were actions the students knew, had in common, and Mindy taught these actions from the bottom-up. Initially tasks started with a simple exploration of how to do the action of "walk", then adding on a variety of expressive possibilities using the movement concepts within the constraint of doing it "fast". For example, she used the movement concepts of direct pathways (space) and sharp turns (effort) that created a nested process to the students learning. The initial action led to more elaborate versions of the combined actions as they grew into related forms, but at the same time unique ways of expressing the action words. Each action, refined by the movement concepts allowed more complexity to develop as the actions recursively expanding into the phasing of dance.

"The idea of the dance is that you are late," Mindy explained; "you have over slept, that is why you are in a rush. Now take up your sleep positions. Oh nice flop Shaun. Good Kirsty it really looks like you are leaning against something."

The infinite variety of sleep positions at different levels, using different combination of body parts signaled a personal quality to each shape.

Drawing on the students common experience (redundancy) of being late Mindy gave purpose to the dance. Then using the movement concepts of body, effort, relationships and space Mindy noted responses from the students, feeding the diversity that each student could use as they explored, experimented and selected appropriate actions that they could then customize. Mindy promoted unique individual solutions that acknowledged the interactions between the individual, task and environmental constraints that shaped movement solutions. This process became an intrinsic motivator as it allowed individuals to autonomously determine their actions and hence further promoted their perceptions of competence. This is much better than a dance teacher trying to enforce adherence to a 'perfect' movement solution found in some traditional approaches to teaching dance. 
"Now I will clap beats of eight. You do your fast, tense walks followed by a spin on the sixth to eighth beat...really whip off into the next walk and so on...CLAP!" The children burst into action, in different directions, their bodies taut and stiff.

"CLAP four, CLAP five and pivot for three. Well done. That's it, keep control...but fast!!" The children whizzed off into tense walks...ready for another spin.

By focusing on the creative way in which children could drape and hang their bodies in sleeping positions, by stressing the dynamic effort quality of walking and pivoting with tension and urgency, by focusing movement in a direct path, the children, with Mindy's guidance, had discovered how to expressively move with their bodies. Mindy's tasks created enabling constraints that proscribed what students could do whilst offer constraints that focused their actions in certain ways, feeding into the intent of the dance. These ongoing tasks framed by the movement concepts and focusing feedback gradually allowed the class to develop control and purpose to their actions as they gained more decentralized control.

The music was then added, broken into phrases of eight. This produced a possibly worrying challenge for the child who felt unable to keep a rhythm, but somehow the supportive atmosphere of playing with the musical challenge created an expectant buzz in the air. As the music played the children used their fingers to mime out their movements. The children were ready.

"Right, into your sleep positions." Mindy ordered. The children rushed to take up their personal stance. Barely able to suppress the tension waiting to explode in their bodies they flopped in unique shapes. The music hissed, there was an expectant hush, the music started and--the children were seriously late.

This final performance showed how Mindy had created a collection of learners as a system that learned. Their actions in the dance formed an autocatakinetic system where skills were learned in situ and in response to their peers; some movements became embodied memories being retained others discarded within the context of exploring for the dance. The system sustained itself from the actions of each student interacting with each other, the music and the imagery. These constraints came together through teacher mediation guiding students' movements in a meaningful, expressive pattern.

As Mindy watched the class she could see Jason, with a huge grin fixed from ear to ear, rushing earnestly around the gym within the phrasing of the music. He, among others during the lesson, had received well-earned praises for creativity and the display of growing body awareness. The children's movements showed a sense of control, rhythm and purpose, their movements indicated focused, playful vitality.

The dance ran over three lessons, developing the idea of sleeping in and being late for school...missing several buses. At the end of the lessons the unruly class that normally had to be policed into a line to exit the gymnasium lined up automatically and quietly buzzed with excitement. The principal was amazed, so was Mindy.

Mindy designed her lessons for intentional emergence. She allowed the dance actions to come from the diversity in the group, recognizing that students' learning was structurally determined; Mindy had encouraged them to adapt their actions to the tasks, each other and the music. The students self-organized around the themes of dance, they became a system that as a collective learned to dance. In this final section I will take this idea further focusing on how the teacher creates the conditions for collective learning in games.

\section{INVENTING GAMES AND COMPLEXITY THINK- ING: WHEN LEARNERS LEARN BEST IN}

Inventing games (IG) is a game centered approach where the teacher creates the conditions for learners to design their own games to initiate their understanding of how rules affect game play, and then how to play tactically to gain advantage in the game [36]. Skill development emerges in response to the challenge of engaging in a game that continuously evolves as the game design develops more challenging game play environments. This final section will focus on the notion of how learners learn best from a complexity thinking perspective, and in particular, how as a collective of learners they can design games that enable each person to engage in the game, learning skills in situations that are socially supportive and where the spaces to play in the game are able to accommodate different player abilities.

To initiate an inventing games approach Butler and Hopper [3] have developed the following nine steps from working with elementary and secondary PE teachers.

\section{GROUPING, ROLES and DEMOCRATIC PROCESS}

A key idea is creating a collective learning process in small groups of 4 to 6 students depending on age and prior ability. This group forms a learning system with roles assigned within the group such as official to record rules and draw game set-up, coach to develop practices and suggest modifications to equipment, team manager to facilitate discussion/consensus and equipment monitor to select/organize and make sure equipment is used safely. The group decides on a democratic way to ensure all have input in the decisionmaking process.

\section{GAME FORM to Explore}

Games within a lesson are normally developed in one game category such as net/wall (tennis, squash), territory/invasion (basketball, rugby), target (golf, bowls) or batting/fielding (cricket, baseball) games [37]. For example, to familiarize students with the net/wall games category the teacher can explore the game category by teaching a simple game. As noted by Butler and Hopper [3] this game can be "developed either as a co-operative game form (such as "keep the ball up after one bounce working with your partner") or a competitive game form (for instance, "try to send the ball into a court area in such a way as to make it difficult for you partner to return the ball”).” In these simple game 
forms the teacher is focused on getting students to find the ball and equipment that they can use to do the task. As the students can maintain the ball in a rally the teacher then focuses on developingstudents'effective off-the-ball movements in order to relocate to where the ball will bounce. For example, if two players were trying to send the ball up in the air to come down and bounce on a small target to score a point, the player waiting to receive the ball can move to a space behind the target, opposite their partner who will send the ball towards the target. As indicated in Hopper (2011), this movement, prompted by teacher questioning "where to you go after sending the ball?" sets up the player with time to adjust to where the ball is actually sent and gives them time to co-ordinate their actions to successful receive the ball and then send the ball towards the target (sending could be catching and tossing or striking the ball after a touch to control it). The key is that the two players can rally, keep the ball going in a simple game structure.

\section{EXPERIMENT \& SELECT for Fairness and Flow}

Once the students are able play in the selected game form then in their groups with assigned roles, they design their own games based on the game form initiated by the teacher. Developing on the net/wall game form example they may start with the primary aim of "keep the ball in the court area more often than the opponent" and then add on rules such as (1) the ball can only bounce once, (2) the ball must go over a line on the wall, and (3) players must send the ball alternately from where they catch it. Other groups may be playing in a space in the gymnasium playing over lines and net. Some groups may be using beach balls and their hands to strike the ball; other groups might be using paddle bats and a sponge ball. The teacher emphasizes that the games need to be fair in that all players, regardless of ability must be able to play in the game and that each player does not have to send the ball in the same way. The initial focus is on creating a co-operative game that flows so that all players can play and rally sending the ball back and forth.

\section{ADAPTATION SCORING for Everyone}

As players are able to create a game that everyone can engage in, then the groups implement a scoring system where the outcome of the game results in modification of the game structure to make it more challenging for the successful player. Hopper (2011) calls this modification by adaptation. As he states,

In modification by adaptation the game is modified to increase the challenge to the player who was successful on the previous game encounter. Changes can be made in relation to the constraints of the game, such as space, scoring, or rules conditioning play or number of players, in order to ensure the outcome of the game is close, and for the unanticipated to happen during game play (p. 6).

This means that in a game where the ball is hit against the wall a person who wins the first game might have the size of the court they can hit into reduced making it easy for their opponent to cover the target area or a second line might be added higher on the wall so that they have to hit over this line giving their opponent more time to play a shot.

\section{REFINE for Flow}

Once the adaptation scoring system is introduced then the players make final refinements to their games making sure the competitive games enable a good chance for rallies. Also, that they are positioning themselves effectively after sending the ball in order to cover the target area of their opponent.

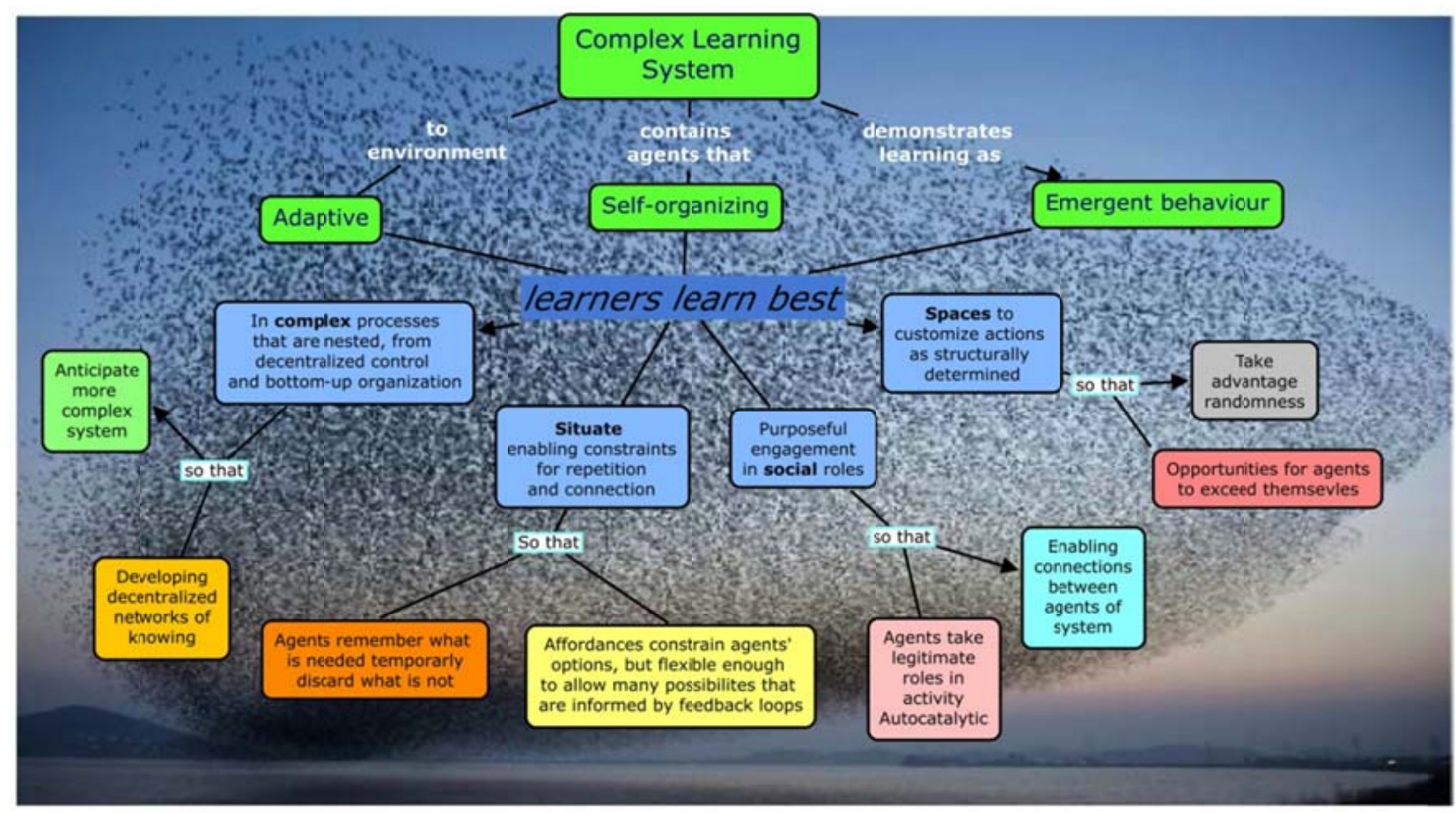

Fig. (4). Complexity thinking features for an inventing games lesson. 
The teacher may suggest tactical or skill pointers to the coaches in each group in regards to court positioning or ball contact and basic follow-though to help control force and directional control of the ball.

\section{REVIEW for Fun}

The final stage is to review the game, writing out the final rules and drawing the set-up so that the game is ready to be shared with other players. The game should be fun at this stage if the group has adapted the task/environment constraint interactions. This will mean that players of different abilities can engage in a challenge that is just at the edge of their ability.

\section{SHOWCASE (Assess)}

The officials stay with each game to explain it to the new players and the rest of the group rotate to a new game. Players then engage in the new games to assess how well they meet the requirements of the game being fair, fun, flowing and for everyone. Players offer feedback and if appropriate suggestions.

\section{REVISE (Feedback)}

Based on playing other games and the feedback from visiting players, each group then makes further revisions to their games. This can include adding on new equipment or extending the rules to address interpretation issues by visiting players.

\section{TACTICAL AND SKILL Practice}

The previous eight steps, spread over several lessons, create game category related game forms that all students are able to play. This is an ideal situation from which to encourage students to explore tactical problems and skill practices related to their game. For example, "where should you position yourself after sending the ball short?" or "how do you strike the ball to get more accuracy?" Learning to control the ball in games you have created offers the basis to transfer these ideas into more specific game units such as volleyball, tennis or badminton. As noted by Davids et al. [24] "the essence of transfer is being able to adapt an existing movement pattern to a different set of ecological constraints" (p. 95). The IG approach encourages students to adapt an existing movement pattern, a stable base for supporting for actions, to a landscape of ecological constraints they have learned to manipulate in order to enable success through challenging engagement.

The IG stages offer a core basis for engaging students with the constraint-led approach and non-linear pedagogy. The IG process focuses on game-based learning where a game form is created that all students can engage in and from which they can gain understand about how to play. This understanding from an IG approach within a Net/Wall game category can then be transferred in formal units of instruction on adult games such as tennis, volleyball and badminton units.

\section{Applying Complexity Thinking to IG}

In relation to complexity thinking, Fig. (4) highlights how IG offers the conditions that could set up the situation for how learners learn best. The structure of the IG process focuses students on adapting to the constraints of the game, self-organizing as a group with a common intent and through trying out ideas selecting the emergent processes that work for them.

Critically, the diversity within any group is an asset; the game will become more dynamic and engaging if it is designed to accommodate all abilities levels and different prior understandings of games within the game category. Learners learn best when opportunity spaces are created that allow them to customize how they play to their structural needs. Groups need a mixture of abilities and prior experiences in games within a games category so that the randomness of prior experiences allow a unique game to develop not just ones based on rule-bound adult games played by the more able students. This allows all students to engage in a game that will allow them to exceed their pre-existing abilities as they transfer existing motor patterns into new landscapes of game play spaces. This makes total sense based on a constructivist view of learning as learners can only learn from the foundation of their prior experiences; their learning is structurally determined.

The social roles and responsibilities in IG, such as coach and official, contribute to a collective group identity and increased student engagement. As noted in the sport education model of instruction, assigning these type of roles to students in games leads to more self-directive behaviour [38, 39]. Across lessons the roles can be rotated among group members with associate responsibilities addressed as students learn to co-create a shared game that they collectively own. Teachers may have to assist students in creating democratic processes through neighbourly interactions, but as the students learn to try ideas out, adapt the games based on experiments and then select through consensus how to move the game forward, the players in the game becomes a learning system. When each group member is purposefully engaged in the game, invested in the making a game that flows, skills evolve from an autocatakinetic process through the co-mingling of their roles and common intent. This captures the key ideas of social constructivism and situated learning as students learn through joint participation, creating a community of practice in shared and situated learning experiences [40, 41].

Learning becomes situated in games that co-evolve to the players as the players adapt to the game. The notion of $\boldsymbol{e n a -}$ bling constraints is core to this process as students learn to manipulate the rules, equipment and court area through repetition of ideas tried out, retained, adapted and discarded. They note down ideas to remember what works but importantly have discard ideas that later they may recall to be reworked back into the game as their abilities develop and the game evolves.

The net/wall games students create are always different but all have a common root rule associated with "keep the ball in the opponent's court." It becomes clear that games within a game category elicit similar tactical demands and skill patterns that transfer across games and feed into more 
complex and demanding adult games. This shows the nested nature of games and how invented backyard games and informal playground play serves as a critical role in the transfer of game play understandings from modified games to the formal games we play in society [27]. The bottom-up organization process of the IG approach allows students to learn games by reading how the rules and game structure affect how you play the game, shifting from the simplest game form to more complex "adult-like" games. Through this process students create an embodied language of knowing the game by playing it, adding in constraints as needed, rendering explicit the cultural conditions that delimit possible ways of playing. This process connects to the cultural and critical theories of learning allowing students to critique discourses of playing games. For example, the goal of playing to beat other players with the same game structures for all players leads to elimination of less able students, instead the discourse of adapting games to challenge the successful player embraces the idea of equality of opportunity, creating games that engage all players with increasing opportunities to win for those who are at first not successful.

Ultimately IG creates a decentralized control process to learning to play games. The iterative process of co-creating games with others can only encourage students to play games outside of formal PE lessons. Learning to adapt constraints, within a community of game players offers great potential for enabling students to learn to play, develop and evolve games in their own free time with others in a variety of environments. In this way IG connects to notions associated with ecological theories of learning. In these theories students learn to play modified games within a collective system of players. This system of players in turns learns as part of a larger more complex web of relations that connects and feeds into adult games played in society. Modified games then become linked to and contribute to the adult games in society as novice players engage with a sense of connection to these games.

\section{CONCLUSION}

Throughout this paper I have explored learning as an emergent process that results from the conditions created by the teacher to enable students to come together within a complex learning system. Complexity thinking and the constraints-led approach both advocate teaching as focused on enabling the learner to adapt to the task/environmental constraints. Complexity thinking further encourages teachers to consider a class of students as a learning system with features such as nested, inter-connected, diverse, afforded patterns of acting within constraints, subject to bottom-up organization from decentralized control, and developing skills from co-mingle roles in the pursuit of a common goal. If lessons are structured in such a way as to nurture these features, encouraging students to become agents of complex system, then I suggest that learning can take place that can enhance the experience of physical education. By applying a complexity thinking frame of reference one can create the conditions in PE lessons that form self-sustaining learning systems. Learning then becomes emergent through social, situated and complex spaces that enable more physically engaged students.

\section{REFERENCES}

[1] Chow JY, Davids K, Button C, Shuttleworth R, Renshaw I, Araujo D. The role of nonlinear pedagogy in physical education. Rev Educ Res 2007; 77(3): 251-78.

[2] Wall J, Murray N. Children and movement. Dubuque, IA: Wm. C. Brown Publishers 1994.

[3] Butler J, Hopper T. Inventing net/wall games for all students. Active Healthy Mag 2011; 18(3/4): 5-9.

[4] Hopper T, Sanford K, Clarke A. Game-as-teacher and game-play: Complex learning in TGfU and video games. In: Hopper T, Butler J, Storey B, Eds. TGfU simply good pedagogy: understanding a complex challenge. Ottawa: Physical Health Education 2009; pp. 201-12.

[5] Hopper TF, Sanford K. Occasioning moments in game-as-teacher: Complexity thinking applied to TGfU and video gaming. In: Butler J, Griffin L, Eds. Second TGfU book: Theory, research and practice. Windsor: Human Kinetics 2010.

[6] Hopper T. Complexity thinking and creative dance: creating conditions for emergent learning in teacher education. PHEnex J 2010; 2(1): 1-20.

[7] Mennin S. Complexity and health professions education: a basic glossary. J Eval Clin Pract 2010;16: 838-40.

[8] Mauldon E, Redfern H. Games teaching. London: Macdonald and Evans Publishers 1981.

[9] Thorpe R. A demonstration of a different focus. In: Thorpe R, Bunker D, Almond L, Eds. Rethinking games teaching. Loughborough: University of Technology 1986; pp. 17-24.

[10] Light R. Complex learning theory - its epistemology and its assumptions about learning: implications for physical education. J Teach Phys Educ 2008; 27: 21-37.

[11] Barab SA, Plucker J. Smart people or smart contexts? Cognition, ability, and talent development in an age of situated approaches to knowing and learning. Educ Psychol 2002; 37(3): 165-82.

[12] Davis B, Sumara D, Luce-Kapler R. Engaging minds: changing teaching in a complex world. New York: Routledge 2008.

[13] Piaget J. Science of education and the psychology of the child. In: Coltman TbD, Ed. New York: Viking Press 1969.

[14] Davis B, Sumara D. Complexity and education: inquires into learning, teaching and research. London: Lawrence Erlbaum 2006.

[15] Vygotsky L. Mind and society. In: Cole M, John-Steiner V, Scriber S, Souberman E, Eds. Mind and society. Cambridge MA: Harvard University Press 1978.

[16] Wertsch J. Vygotsky and the social formation of mind. London: Harvard Press 1985.

[17] Lave J, Wenger, E. Situated learning: legitimate periperal participation. New York: Cambridge University Press 1991.

[18] Freire P, Macedo D. Literacy: reading the world and the word. Massachusetts: Bergin \& Garvey Publishers, Inc 1987.

[19] Barab SA, Cherkes-Julkowski M, Swenson R, Garrett S, Shaw RE, Young M. Principles of self-organization: learning as participation in autocatakinetic systems. J Learn Sci 1999; 8(3): 349-90.

[20] Gee J. Good video games and good learning. New York: Peter Lang 2007.

[21] Mason M. Complexity theory and the philosophy of education. Educ Philos Theory 2008; 40(1): 4-18.

[22] Davis B, Sumara D. Complexity science and educational action research: toward a pragmatics of transformation. Educ Action Res 2005; 13(3): 453-66.

[23] Johnson S. Emergence: The connected lives of ants, brains, cities and software. New York: Scribner 2001.

[24] Davids K, Button C, Bennett S. Dynamics of skill acquisition: a constraints led approach. Windsor, ON: Human Kinetics 2008.

[25] Newell KM. Constraints on the development of coordination. In: Motor development in children. In: Wade M, Whiting H, Eds. Aspects of coordination and control. Dordrecht The Netherlands: Martinus Nijhoff 1986; pp. 341-60. 
[26] Davis WE, Burton A. Ecological task analysis: translating movement behavior theory into practice. Adapt Phys Activ Q 1991; 8(2): 154-77.

[27] Renshaw I, Chow JY, Davids K, Hammond J. A constraints-led perspective to understanding skill acquisition and game play: a basis for integration of motor learning theory and physical education praxis? Phys Educ Sport Pedagogy 2010; 15(1): 1-21.

[28] Hopper T. Game-as-teacher: Modification by adaptation in learning through game-play. Asia Pac J Health Sport Phys Educ 2011; 2(2): 3-21.

[29] Richardson K, Cilliers P. What is complexity science? A view from different directions. Editorial. Emergence 2001; 3(1): 5-22.

[30] Carline S. Lesson plans for creative dance: connecting with literature, arts and music. Champaign IL: Human Kinetics 2011.

[31] Nilges LM. Ice can look like glass: a phenomenological investigation of movement meaning in one fifth-grade class during a creative dance unit. Res Q Exerc Sport 2004; 75(3): 298-314.

[32] Hopper T, Madill L, Bratsch C, Cameron K, Coble J, Nimmon L. Multiple voices in health, sport, recreation and physical education research: revealing unfamiliar spaces in a polyvocal review of qualitative research genre. Quest 2008; 60: 214-35.
[33] Rinehart R. Fictional methods in ethnography: believability, specks of glass and chekhov. Qual Inq 1998; 4(2): 220-4.

[34] Sparkes A. Telling tales in sport and physical activity: a qualitative journey. Champaign, IL: Human Kinetics 2002.

[35] Narayan K. Tools to shape texts: what creative nonfiction can offer ethnography. Anthropol Hum 2007; 32(2): 130-44.

[36] Almond L. Games making. In: Thorpe R, Bunker D, Almond L, Eds. Rethinking games teaching. Loughborough: University of Technology 1986; pp. 67-70.

[37] Werner PA, L. Model of games education. J Phys Educ Recreat Dance 1990; 61(4): 23-7.

[38] Clarke G, Quill M. Researching sport education in action: a case study. Eur Phys Educ Rev 2003; 9(3): 253-66.

[39] Kinchin G, O'Sullivan M. Incidences of student support for and resistance to a curricular innovation in high school physical education. J Teach Phys Educ 2003; 22(3): 245-60.

[40] Kirk D, Kinchin GD. Situated learning as a theoretical framework for sport education. Eur Phys Educ Rev 2003; 9(3): 221-35.

[41] MacPhail A, Kirk D, Kinchin G. Sport education: promoting team affiliation through physical education. J Teach Phys Educ 2004; 23(3): 106-22.

Received: August 16, 2011

Revised: May 25, 2012

Accepted: May 30, 2012

(C) Timothy Hopper; Licensee Bentham Open.

This is an open access article licensed under the terms of the Creative Commons Attribution Non-Commercial License (http://creativecommons.org/licenses/ by-nc/3.0/) which permits unrestricted, non-commercial use, distribution and reproduction in any medium, provided the work is properly cited. 